\title{
Extrusão de molares com aparelho platô fixo: relato de caso clínico
}

\author{
Molar extrusion with fixed plateau appliance: clinical case report \\ Extrusión molar con aparato de meseta fija: reporte de caso clínico
}

\section{Resumo}

Objetivo: O objetivo deste trabalho foi relatar um caso clínico de extrusão de dentes posteriores através do uso de aparelho platô fixo com intuito de correção e alinhamento. Metodologia: Partindo da permissão da paciente por meio do Termo de Consentimento Livre e Esclarecido (TCLE) em partilhar sua imagem para devido fim, o presente estudo trata de um relato de caso clínico de cunho analítico descritivo (Pereira et al., 2018). Relato de Caso Clínico: Paciente M.B.S.D.S., melanoderma, gênero feminino, 11 anos e 9 meses, compareceu com seu responsável a FAMETRO: Clínica de Atenção Integrada Infantil, para tratamento ortodôntico por indicação da odontopediatra. Apresentava boas condições de saúde em geral, sem comprometimento sistêmico relevante. Após anamnese e exame clinico foram solicitados os exames cefalometrico, radiografia panorâmica, laudos radiográficos, fotografias intrabucais e perfis. Considerações Finais: Desta maneira a utilização do aparelho para a correção da mordida profunda é aconselhável, pois esse procedimento pode ajudar a estética facial final.

Palavras-chave: Má oclusão; Sobremordida; Aparelhos fixos.

\begin{abstract}
Objective: The aim of this study was to report a clinical case of posterior teeth extrusion using a fixed plateau appliance with the aim of correction and alignment. Methodology: Based on the patient's permission through the Informed Consent Form (FICF) to share her image for the proper purpose, this study is a clinical case report of a descriptive analytical nature (Pereira et al., 2018). Clinical Case Report: Patient M.B.S.D.S., melanoderma, female, 11 years and 9 months, attended with her person responsible for FAMETRO: Integrated Child Care Clinic, for orthodontic treatment as indicated by the pediatric dentist. He presented good health conditions in general, without relevant systemic involvement. After anamnesis and clinical examination, cephalometric examinations, panoramic radiography, radiographic reports, intraoral photographs and profiles were requested. Final Considerations: In this way, the use of the device to correct deep bites is advisable, as this procedure can help the final facial esthetics.
\end{abstract}

Keywords: Malocclusion; Overbite; Fixed appliances.

\section{Resumen}

Objetivo: El objetivo de este estudio fue reportar un caso clínico de extrusión de dientes posteriores utilizando un aparato de meseta fijo con el objetivo de corrección y alineación. Metodología: Con base en el permiso de la paciente a través del Término de Consentimiento Informado (FICF) para compartir su imagen con el propósito adecuado, este estudio es un reporte de caso clínico de naturaleza analítica descriptiva (Pereira et al., 2018). Reporte de Caso Clínico: Paciente M.B.S.D.S., melanoderma, del sexo femenino, 11 años y 9 meses, atendida con su responsable de FAMETRO: Clínica Integrada de Cuidado Infantil, para el tratamiento de ortodoncia indicado por el odontopediatra. Presentaba buen estado de salud en general, sin afectación sistémica relevante. Tras anamnesis y exploración clínica, se solicitaron exploraciones cefalométricas, radiografía panorámica, informes radiográficos, fotografías intraorales y perfiles. Consideraciones finales: De esta forma, se aconseja el uso del dispositivo para corregir mordidas profundas, ya que este procedimiento puede ayudar a la estética facial final.

Palabras clave: Maloclusión; Sobremordida; Electrodomésticos fijos. 


\section{Introdução}

A oclusão pode ser definida como a relação estática e funcional que os dentes mantem entre si, com os maxilares, com a musculatura peribucal e com o esqueleto craniofacial como um todo (Silva Filho et al., 2012, p. 466.)

A Organização Mundial da Saúde (1962) descreve a maloclusão como conjunto de anomalias dentofaciais que causam deformação ou impedem a função e que, portanto, requerem tratamento (Brasil, 2018, p.56).

Vários estudos têm demonstrado a relação entre características faciais e as alterações esqueléticas e oclusais nas maloclusões, concluindo que informações sobre anormalidades esqueléticas e dentárias podem ser derivadas da análise de tecidos moles. (Siécola et al., 2017, p. 88).

As alterações dentoesqueléticas, podem proporcionar efeitos negativos funcionais e estéticos, interferindo na qualidade de vida dos indivíduos acometidos (Brasil, 2018).

Com intuito de organizar um método diagnóstico Capelloza Filho (2004) determinou parâmetros para a observação da face do indivíduo de acordo com seu padrão de crescimento, considerando a limitação das medidas faciais em expressar forma ou normalidade. Dentro deste aspecto os indivíduos podem ser classificados como: Padrão facial I, II e III, face longa ou curta. O paciente face curta apresenta o terço inferior diminuído em relação ao terço médio da face, lábios comprimidos, maxila com expressão adequada e excesso da linha queixo-pescoço, devido à rotação anti-horária da mandíbula. (PETEAN, 2016, p. 07).

Dentro desse contexto a ortodontia tem por objetivo o estudo, a prevenção, a interceptação e a correção das anomalias de posição, relação e harmonia dentomaxilofaciais, durante a fase de crescimento, com a finalidade de reestabelecer a oclusão e as funções bucais normais (Janson, et al., 2013, p. 97).

A sobre mordida exagerada é um tipo de má oclusão que apresenta etiologia multifatorial e necessita de um diagnóstico diferencial elaborado e específico, assim como, a eleição da técnica de tratamento e mecânica adequadas para cada situação clínica e individualizada para cada paciente, de acordo com o padrão esquelético, a direção de crescimento, a linha do sorriso e a distância do lábio ou incisivo inferior, visando alcançar sempre, resultados adequados e estáveis. (Prado, 2016, p.10).

A causa da mordida profunda pode estar relacionada com a perda e desgaste dos dentes posteriores, retrusão mandibular, comprimento dos incisivos superiores e inferiores, altura de cúspide e crescimento vertical da mandíbula, com altura do ramo mandibular e padrão facial (Silva et al., 2014; Lima, et al., 2021, p. 04).

Utilizando modelos de estudo por uma vista lingual Baume (1949), classificou a sobremordida em três tipos: leve, quando os incisivos centrais inferiores ocluem com o terço incisal dos incisivos superiores. Média, quando os incisivos inferiores ocluem com o terço médio dos superiores e exagerada, quando os incisivos inferiores ocluem com a protuberância do cíngulo dos superiores ou com a gengiva palatina (Aguiar, 2017 p. 02).

Um dos aparelhos indicado na correção de mordida profunda é o platô fixo que permite a extrusão de pré-molares e molares, e intrusão dos incisivos inferiores, provocando desta maneira um aumento do terço inferior da face, por esta razão é utilizado em pacientes braquifacial ou mesiofacial (Moro, et al., 2017; Tanaka, 2021, p.14).

A extrusão dos dentes posteriores causa impacto direto na quantidade de trespasse vertical na região anterior. Para cada $1 \mathrm{~mm}$ de extrusão posterior, o trespasse vertical anterior diminui 2 mm. (PROFFI; 1995; Santos \& Moro, 2018, p. 06).

Diante disso, o objetivo deste trabalho foi relatar um caso clínico de extrusão de dentes posteriores através do uso de aparelho platô fixo, com intuito de correção e alinhamento para que futuramente seja realizado tratamento com aparelho ortodôntico fixo. 


\section{Metodologia}

Partindo da permissão da paciente por meio do Termo de Consentimento Livre e Esclarecido (TCLE) em partilhar sua imagem para devido fim, o presente estudo trata de um relato de caso clínico de cunho analítico descritivo (Pereira et al., 2018), realizado na clínica odontológica do CEUNI Fametro, na disciplina de estágio supervisionado em Clínica Integrada II, do curso de graduação do Centro Universitário Fametro.

\section{Resultados e Discussão}

Paciente M.B.S.D.S., melanoderma, gênero feminino, 11 anos e 9 meses, compareceu com seu responsável a FAMETRO: Clínica de Atenção Integrada Infantil, para tratamento ortodôntico por indicação da odontopediatra. Apresentava boas condições de saúde em geral, sem comprometimento sistêmico relevante. Após anamnese e exame clinico foram solicitados os exames cefalometrico, radiografia panorâmica, laudos radiográficos, fotografias intrabucais e perfis.

Durante o exame clinico extrabucal, obeservou-se assimetria facial com desvio mandibular do terço inferior para o lado direito, selamento labial passivo, tendendo a Padrão Facial II, face curta (Figura 1A). Ao ser analisada a paciente sorrindo, verificou-se sulco mentolabial bem marcado, exposição dos incisivos superiores, ausência de exposição gengival e dos incisivos inferiores (Figura 1B). A análise do perfil mostra um perfil convexo, com proeminência do zigomático, o qual sugere um desenvolvimento adequado da maxila (Figura 1C).

Figura 1. (A-C) Fotografias extra bucais iniciais: A) Frontal; B) Sorriso; C) Perfil.

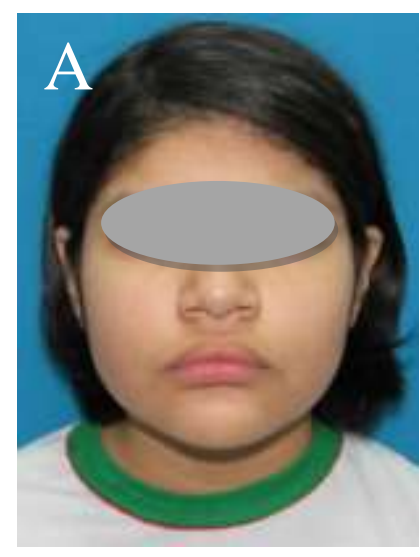

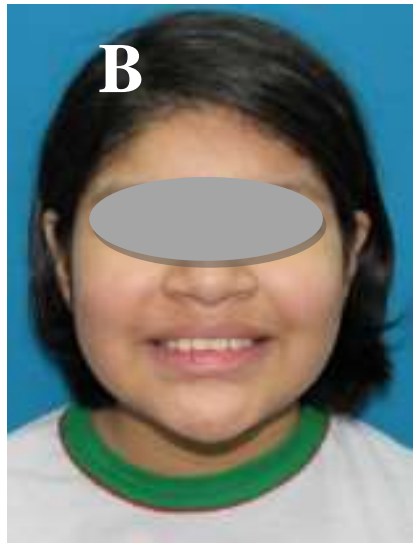

Fonte: Autoria própria.

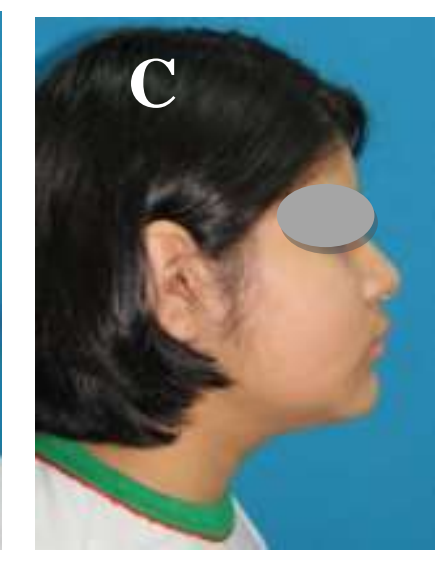

$$
\text { (1) }
$$

Ao ser realizada a avaliação intra-oral foi constatado que a paciente se encontrava na dentição permanente, classe I de molar e canino direito (Figura 2A), classe I de molar e canino esquerdo (Figura 2C), com sobremordida e trespasse horizontal aumentado (Figura 2B). 
Figura 2. (A-E) Fotografias intrabucais iniciais: A) Direita; B) Frontal; C) Esquerda; D) Oclusal Superior; E) Oclusal Inferior.
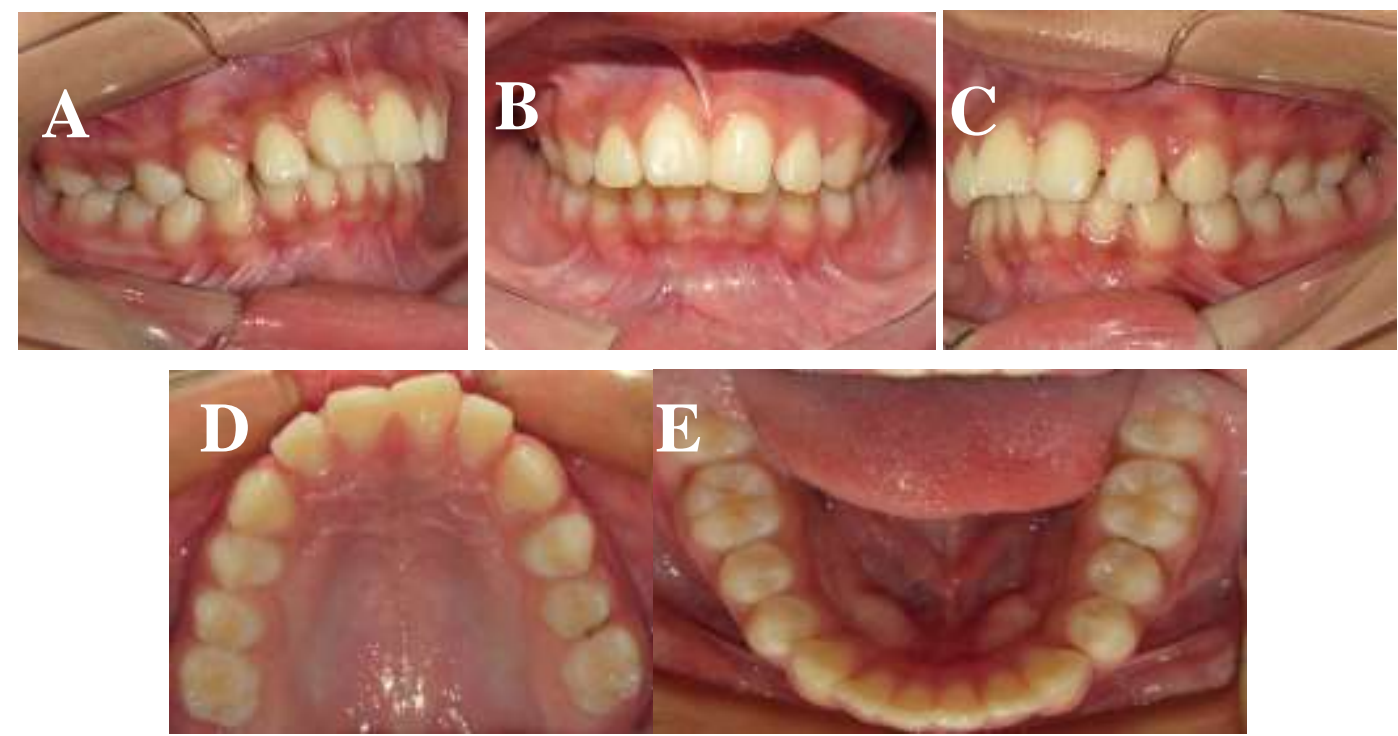

Fonte: Autoria própria.

Na radiografia panorâmica (Figura 3), observou-se a presença de todos os dentes permanentes, com exceção dos terceiros molares, boa estrutura óssea da maxila e da mandíbula, estruturas dentoalveolares normais e sem anomalias.

Figura 3. Radiografia Panorâmica Inicial.

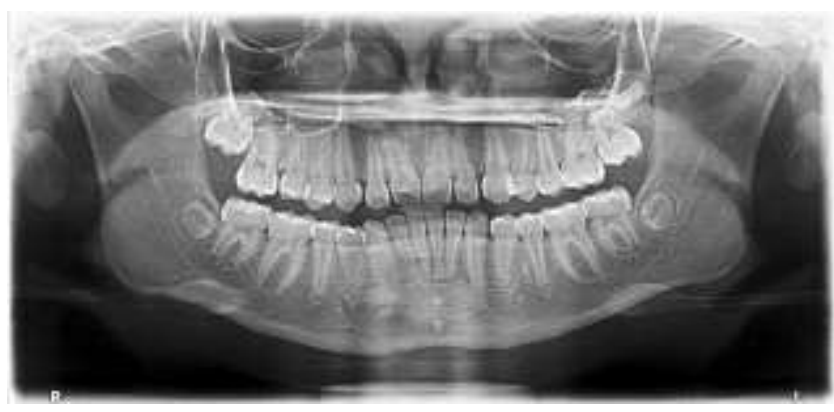

Fonte: Autoria própria.

Na telerradiografia lateral (Figura 4), foi observada a vestibularização dos incisivos superiores e inferiores, ausência de alterações nas vias aéreas e morfologia da sínfise normal.

Figura 4. Teleradiografia Lateral Inicial.

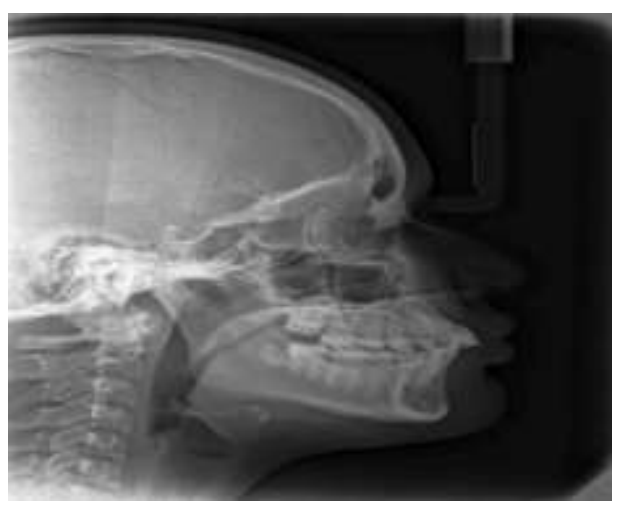

Fonte: Autoria própria. 
Ao ser realizada a análise cefalométrica (Figura 5), observou-se um perfil convexo, com a protrusão maxilar em relação a base do crânio, enquanto a mandíbula estava com um bom posicionamento, classe I esquelética e vestibularização dos incisivos superiores e inferiores.

Figura 5. Traçado Cefalométrico.

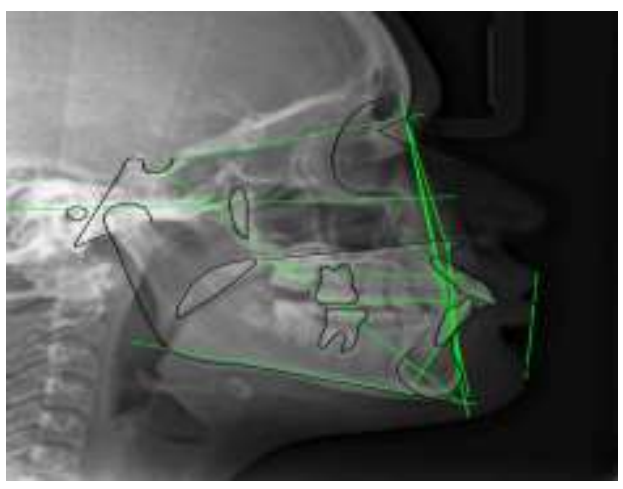

Fonte: Autoria própria.

\section{Plano de Tratamento}

Após avaliação clínica, cefalométrica e radiográfica, foi definido um plano de tratamento para correção da sobremordida, sendo a escolha terapêutica o aparelho do tipo platô fixo.

Primeiramente foram realizados o isolamento relativo e a prova de bandas da marca MORELLI, número 37U/37,5U nos elementos 16 e 26 e em seguida sua correta instalação com os instrumentos: calcador de banda, mordedor de banda e saca banda. (Figura 6).

Figura 6. A - Prova de banda no molar esquerdo; B - Prova de banda no molar direito; C) Instrumental de auxílio para instalação de banda ortodôntica.

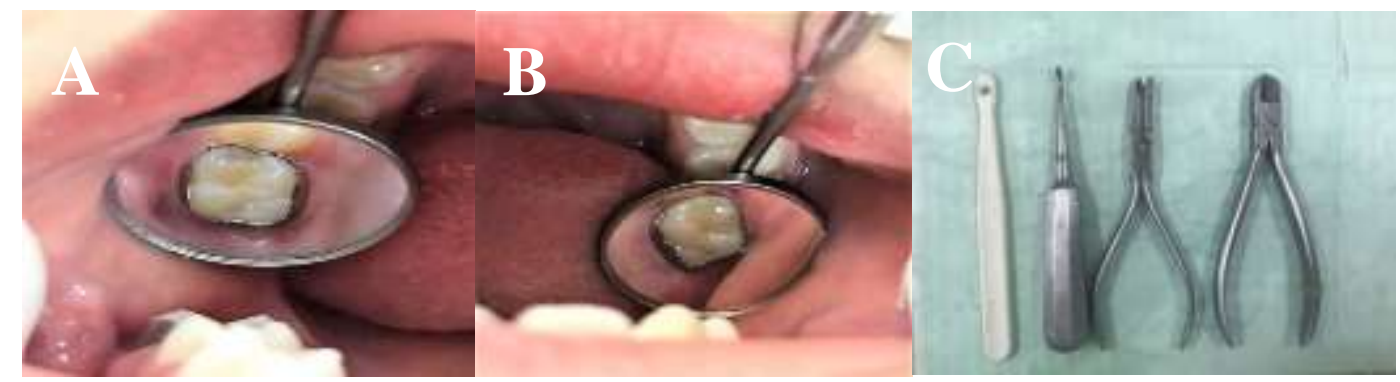

Fonte: Autoria própria.

Em seguida, foi realizada a seleção da moldeira, para melhor precisão e conforto a paciente, foi escolhida moldeira de numeração 4. Logo a execução da moldagem na arcada superior com as bandas adaptadas nos primeiros molares esquerdo e direito, junto com a cópia negativa da arca inferior para obter-se o registro de mordida e oclusão da paciente (Figura 7A - B). Na Figura 7A, as bandas foram presas com um Fio Duro Elástico CrNi - MORELLI 5501050 50mm. 020”, seguindo a moldagem de transferência em cópia positiva sobre o modelo de gesso. (Figura 7). 
Figura 7. A) Bandas adaptadas nos primeiros molares esquerdo e direito; B) cópia negativa da arca inferior; C) Cópia positiva sobre o modelo de gesso.

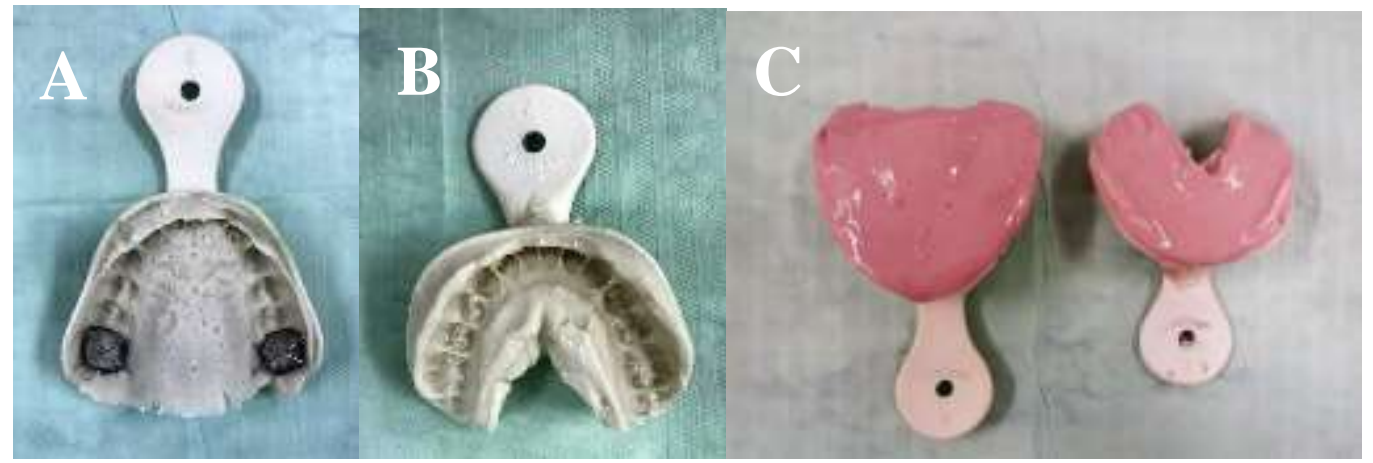

Fonte: Autoria própria.

Os modelos em gesso da arcada superior e inferior foram enviados ao laboratório para confecção do dispositivo.

Passados os 7 dias, ao receber o aparelho, o cimento escolhido foi o Ionômero de Vidro para Cimentação da marca Microglass (Figura 8), devido a sua resistência e biocompatilidade. A proporção recomendada é de 1:1 na medida conforme exige o fabricante.

Figura 8. Material de cimentação utilizado para instalação do aparelho.

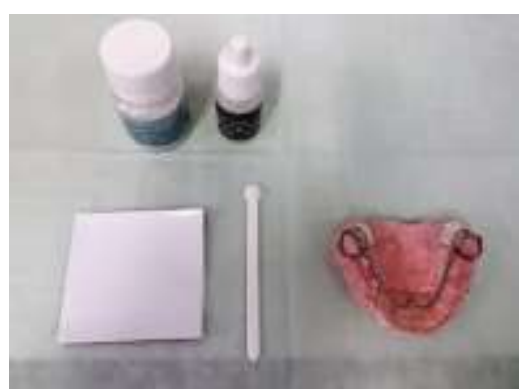

Fonte: Autoria própria.

O cimento foi colocado em toda parte interna da banda. Em seguida foi removido o excesso com o instrumento apropriado e feito da melhor forma para que a colagem ganhasse adaptação a longo prazo, com isso a instalação do aparelho foi realizada. Pode-se observar que o resultado da adaptação do aparelho platô fixo foi satisfatória, como orientação para paciente e responsável foi explicado quanto a adaptação e aos cuidados com o aparelho, com uma boa higienização e bochechos com enxaguante bucal da marca listerine ou clorexidina 0,2\% uma vez ao dia (Figura 9) 
Figura 9. Adaptação do aparelho platô fixo.

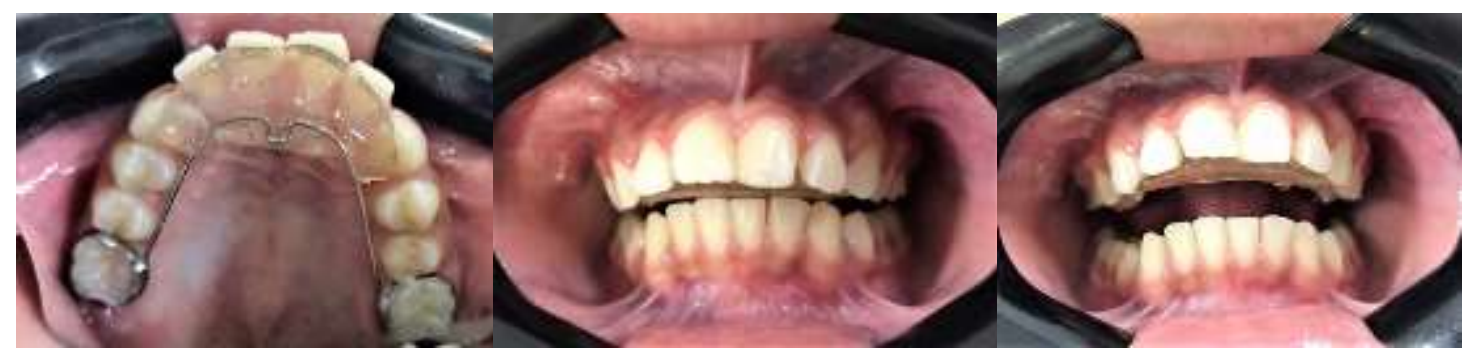

Fonte: Autoria própria.

Observa-se que os dentes posteriores não se tocam, ocasionando a extrusão dos molares e a intrusão dos incisivos inferiores, o aparelho tem o intuito de permitir que a sobremordida seja reversa (Figura 10).

Figura 10. Ausência de toque nos dentes posteriores, ocasionando a extrusão de molares e a intrusão dos incisivos inferiores.

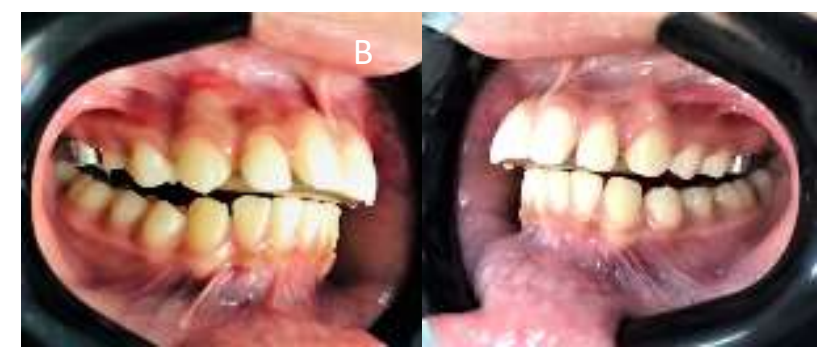

Fonte: Autoria própria.

A intrusão dos incisivos inferiores tem como complexidade a mordida profunda, pois o mecanismo de intrusão se faz necessário para que seja devolvido uma função equilibrada ao sistema estomatognático (Figura 11)

Figura 11. Bloqueio do trespasse vertical.

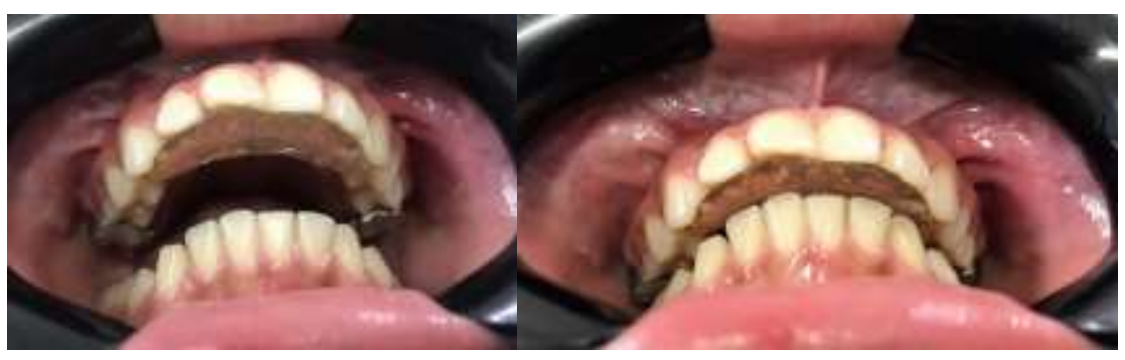

Fonte: Autoria própria.

Percebe-se que ao ocluir, os incisivos inferiores ocluem no batente anterior, bloqueando o contato no terço cervical nos dentes incisivos superiores, facilitando a liberação de oclusão dos dentes posteriores, com o objetivo de extrusão para que a mordida seja aliviada.

A paciente encontra-se em observação quanto ao uso do aparelho e foi encaminhada ao ortodontista para prosseguir com o tratamento ortodôntico fixo. 


\section{Discussão}

O sucesso na correção da mordida profunda de acordo com Brito (2009) depende da seleção correta da mecânica a ser aplicada e de sua perspectiva, por esta razão, vários autores tem estudado e proposto diferentes métodos para alcançá-lo (Lima, et al., 2021 p.02).

Segundo Brito (2009) o planejamento deve estar relacionado as causas da sobremordida exposta, abordando assim o motivo inicial do problema (Moro, 2017 p. 35). Para Strang (1950) alguns dos métodos que auxiliam no diagnóstico da mordida profunda são: uma análise criteriosa dos modelos de gesso do paciente, onde é possível observar, em alguns casos, processo alveolar largo na região lingual dos molares e pré-molares, indicando que aquela região é mal calcificada, logo não resistem às forças mastigatórias e os elementos dentários estão em infra oclusão, o que pode provocar a sobremordida profunda; dentes posteriores abaixo do nível oclusal; incisivos inferiores apinhados, falta de espaço, ou inclinação lingual, geralmente encontrado nos casos de Classe II; curva de Spee acentuada, que caracteriza supra oclusão dos incisivos inferiores e infra oclusão dos dentes posteriores (Coletti, 2017 p. 10).

Para determinar um correto plano de tratamento da mordida profunda, segundo Gil e Maia (1999) é necessário avaliação, através de exame clínico, análise cefalométrica, fotografias e modelos, seguida de uma análise do esqueleto facial, arcada dentária, tecidos moles, função e estabilidade, avaliando o padrão de crescimento. (Coletti, 2017 p. 19)

O problema de mordida profunda para Diamond (1994) e Silva et al (1990), gera graves consequências no sistema estomatognático como um todo (Moro, 2017 p. 40). De acordo com Silva et al., (2014) a sobremordida gera restrições nos movimentos mandibulares, de protrusão e lateralidade, podendo causar problemas na articulação temporomandibular e interferir no processo de crescimento mandibular (Lima, 2019 p. 07).

De acordo com Almeida et al (2010), os métodos mais comuns para correção da sobremordida são: extrusão dos dentes posteriores, inclinação dos dentes anteriores e intrusão dos incisivos superiores e inferiores (Lima et al, 2021 p. 127).

Deregibus et al., (2014) relatam que os planos de mordida anteriores fixos corrigem a distoclusão através da desoclusão dos dentes posteriores, permitindo a erupção de molares e pré-molares enquanto nivela a curva de Spee (Medeiros, 2017 p. 37).

Janson (2008); Cogorni (2013), recomendam a utilização de aparelhos fixos, como a placa de levante fixa que deve ser bandada em molares. Já os autores Grieve (1928); Clark (1976) preconizam o uso de aparelhos removíveis (Coletti, 2017, p. 54).

A mecânica de intrusão dos dentes anteriores para Janson (2008); Brito (2009) é uma opção de tratamento indicada para pacientes que apresentam padrão de crescimento vertical e o procedimento de alinhamento e nivelamento com o uso de fios contínuos promove, em grande parte das vezes, a extrusão de dentes posteriores (Lima, et al., 2021 p. 131).

A extrusão dos dentes posteriores obtida pelo uso de placas de levante (fixas ou removíveis) com apoio anterior ou acessórios colados na lingual dos incisivos superiores de acordo com Pinto (2004) faz com que os dentes posteriores fiquem livres do contato oclusal, tendo sua erupção facilitada e podendo ainda ser forçados ao movimento extrusivo por meio do uso de elásticos verticais posteriores (Coletti, 2017 p.34). Entretanto Nanda (1997) relatou que apesar da extrusão de dente posterior ser a técnica mais comum e mais fácil de ser executada, ela dever ser indicada somente em casos de pacientes classe II divisão 2 ou com altura facial diminuída (Tanaka, 2021 p. 17).

De acordo com Burstone (1977) a extrusão dos dentes posteriores para a correção da mordida profunda em pacientes braquifaciais é aconselhável, pois esse procedimento pode ajudar a estética facial final (Coletti, 2017 p.50). Para Brito et al. (2009) pacientes com padrão de crescimento horizontal a extrusão de dentes posteriores é indicada, já naqueles com padrão vertical, o tratamento é a intrusão de incisivos (Cunha, et al., 2013). 
No caso apresentado o aparelho de escolha foi o do tipo platô fixo, devido seus benefícios no tratamento de levante de mordida, terapêutica de distúrbios verticais relacionados a mordida profunda, liberação da face vestibular dos dentes inferiores e a obtenção de uma estética favorável.

Segundo Janson et al., (2000), dependendo da magnitude da sobremordida e do overjet, a colagem dos braquetes inferiores é prejudicada e a propensão do descolamento de acessórios é alta. Desta forma o uso de platô fixo auxilia na melhora de mordida profunda e na instalação do aparelho ortodôntico fixo.

O batente anterior fixo segundo Ghafari (2013) tem efeito sobre o arco mandibular, facilitando o nivelamento da curva mandibular de Spee, e é muito eficaz em pacientes em crescimento.

\section{Conclusão}

O tratamento da mordida profunda tem por indicação: a extrusão dos dentes posteriores, inclinação dos dentes anteriores e intrusão dos incisivos superiores e inferiores. $\mathrm{O}$ aparelho do tipo platô fixo faz com que os dentes posteriores fiquem livres do contato oclusal, tendo sua erupção facilitada, desta forma promove um resultado adequado para que posteriormente o tratamento com aparelho ortodôntico fixo seja satisfatório.

No caso em questão a paciente continua em tratamento, tento sido encaminhada para o ortodontista para dar prosseguimento e instalação do aparelho fixo.

\section{Referências}

Aguiar, G. A. R., et al. (2018). Sobremordida. Revista FAIPE, 7(2), 16-23 https://revistafaipe.com.br/index.php/RFAIPE/article/view/78.

Brasil. (2018). Arnoldo de Oliveira Junior. Ministério da Saúde Secretaria de Atenção À Saúde Departamento de Atenção Básica (ed.). A Saúde Bucal no Sistema Único de Saúde. Brasília: Ministério da Saúde, 354.

Coletti, D. (2017). Sobremordida Profunda - Etiologia, Diagnóstico e Tratamento em Adultos. 67 f. Monografia (Especialização) - Curso de Ortodontia, Faculdade de Tecnologia de Sete Lagoas, Sertãozinho.

Filhos, O. G. S. (2013). Ortodontia Interceptativa: protocolo de tratamento em duas fases. São Paulo: Editora Artes Médicas Ltda, 564.

Ghafari, J. G., Macari, A. T., \& Haddad, R. V. (2013). Mordida profunda: Opções e desafios de tratamento. Seminários em Ortodontia, 19(4), 253266. doi:10.1053/j.sodo.2013.07.005

Guilherme, J. (2013). Introdução à Ortodontia: parte clínica. São Paulo: Editora Artes Médicas Ltda, 145. (Série Abeno).

Lima, A. A. C., et al. (2021). Tratamento da Sobremordida. REVISTA FAIPE, 11(1), 124-134. <https://www.revistafaipe.com.br/index.php/RFAIPE/article/view/236>.

Moro, K., \& Santos, B. L. (2018). Protocolo de Tratamento de Mordida Profunda. REVISTA FAIPE, 7(2), 31-42, <https://www.revistafaipe.com.br/index.php/RFAIPE/article/view/80>.

Pereira, A. S., Shitsuka, D. M., Parreira, F. J., \& Shitsuka, R. (2018). Metodologia da pesquisa científica. UFSM.

Petean, D. E. M. (2016). Modificações no Perfil Tegumentar Geradas pelo Tratamento Ortodôntico. Sertãozinho: Facsete Faculdade Sete Lagoas, 31.

Prado, M. M. S. (2016). Mordida Profunda: Etiologia, Diagnóstico e Mecânicas de Tratamento na Dentadura Permanente. 34. Monografia (Especialização) Curso de Ortodontia, Faculdade Facsete, Ribeirão Preto.

Siécola G. S., Capelozza, L., Filho, L. D. C., \& Janson, G. H. J. F. C. (2017). Análise Facial Subjetiva e sua Correlação com as Relações Dentárias. Dental Press J Orthod., 22(2):87-94. 10.1590/2177-6709.22.2.087-094.oar

Tanaka, P. Y. (2021). Mordida Profunda: Formas de Tratamento na Dentição Mista e Dentição Permanente. 20 f. Monografia (Especialização) - Curso de Ortodontia, Faculdade de Tecnologia de Sete Lagoas, Araçatuba. 